\title{
Orofacial antinociceptive activity and anchorage molecular mechanism in silico of geraniol
}

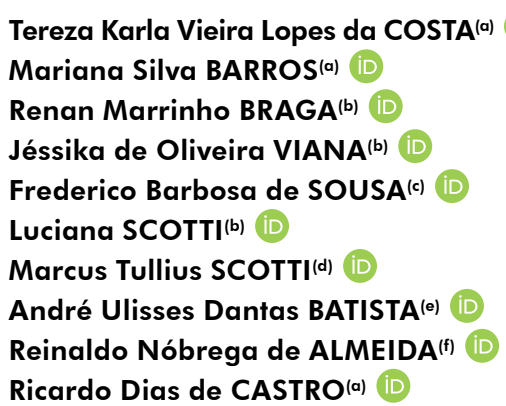

(a) Universidade Federal da Paraíba - UFPB, Faculty of Dentistry, Department of Clinical and Social Dentistry, João Pessoa, PB, Brazil.

(b) Universidade Federal da Paraíba - UFPB, Faculty of Pharmacy, Department of Pharmaceutical Sciences, João Pessoa, PB, Brazil.

(c) Universidade Federal da Paraíba - UFPB, Faculty of Dentistry, Department of Morphology, João Pessoa, PB, Brazil.

(d) Universidade Federal da Paraíba - UFPB, Faculty of Chemistry, Department of Chemistry, João Pessoa, PB, Brazil.

(e)Universidade Federal da Paraíba - UFPB, Faculty of Dentistry, Department of Restorative Dentistry, João Pessoa, PB, Brazil.

(f) Universidade Federal da Paraíba - UFPB, Institute of Drugs and Medicines Research, Department of Physiology and Pathology, João Pessoa, PB, Brazil.

Declaration of Interests: The authors certify that they have no commercial or associative interest that represents a conflict of interest in connection with the manuscript.

\section{Corresponding Author:}

Ricardo Dias de Castro

E-mail: rcastro@ccs.ufpb.br

htips://doi.org/10.1590/1807-3107bor-2020.vol34.0094

Submitted: March 25, 2020

Accepted for publication: June 22, 2020

Last revision: July 6, 2020
Abstract: We aimed to evaluate the orofacial antinociceptive effect of geraniol in mice and its molecular anchorage mechanism. Seven mice per group (probabilistic sample) were treated with geraniol (12.5, 25 and $50 \mathrm{mg} / \mathrm{kg}$, i.p.), morphine $(6 \mathrm{mg} / \mathrm{kg}$, i.p.) and vehicle (saline + Tween 80 at $0.2 \%$, i.p.) 30 minutes prior to the beginning of the experiment. Injecting glutamate $(25 \mu \mathrm{M})$, capsaicin $(2.5 \mu \mathrm{g})$ and formalin (2\%) into the right upper lip (perinasal) of the mouse induced nociception. Behavioral analysis of the animals considered the friction time (in seconds) of the mentioned region using hind or front paws by a researcher blinded to the treatment groups. The statistical analysis was performed blindly, considering $\alpha=5 \%$. The results showed that in the glutamate and capsaicin tests, concentrations of $25 \mathrm{mg} / \mathrm{kg}$ and $50 \mathrm{mg} /$ $\mathrm{kg}$ presented antinociceptive activity $(\mathrm{p}<0.005$, power $>80 \%)$. In the formalin test, geraniol was able to reduce nociception at a concentration of $50 \mathrm{mg} / \mathrm{kg}$ ( $\mathrm{p}<0.005$, power $>80 \%$ ). In the molecular anchorage study, high values of binding between the evaluated substance and receptors of glutamate were observed (metabotropic glutamate receptor, -87.8501 $\mathrm{Kcal} / \mathrm{mol}$; N-methyl-D-aspartate, -86.4451 Kcal/mol; $\alpha$-amino-3hydroxy-5-methyl-4-isoxazole propionic acid, -85.6755 Kcal/mol). Geraniol presented orofacial antinociceptive activity, probably by interacting with glutamate-related receptors.

Keywords: Analgesics, Non-Narcotic; Analgesia; Monoterpenes; Pain Management; Biological Products.

\section{Introduction}

Orofacial pain is defined as pain in the soft or mineralized tissues (skin, blood vessels, bone, teeth, glands, and muscle) of the oral cavity and face. It may be located on the head and/or neck or be associated with cervicalgia, primary headache, and rheumatic disorders, such as fibromyalgia and rheumatoid arthritis. The main sources of orofacial pain are odontogenic problems, headache, neurogenic disorders, musculoskeletal pain, psychogenic pain, cancer, infection, autoimmune phenomena, and tissue trauma. ${ }^{1}$

This problem may have biological repercussions and impact the quality of life of affected individuals. Patients may exhibit physiological dysfunctions, leading to a higher intake of medications, sleep disorders, 
dietary changes, and leave of absence from work. Given its associated morbidity, orofacial pain may be considered a public health problem..$^{2,3}$ The prevalence of orofacial pain may be $30.2 \%$ in developing countries, and this situation can negatively impact daily life, as it is associated with functional limitation, psychological discomfort, disabilities, and handicapness. ${ }^{4}$

Pharmacological agents represent the basis of treatment, and the choice of medication depends on the diagnosed pain type. Opioids, tricyclic antidepressants, anticonvulsants, nonsteroidal anti-inflammatory drugs (NSAIDs), and muscle relaxants are the main classes of drugs used for relief in acute and chronic cases. ${ }^{5}$ However, there is no ideal drug to treat pain in the orofacial complex because although the medications available are effective, they are associated with adverse events, including gastrointestinal, hepatic and kidney injury; allergic reaction; and chemical dependence. ${ }^{6}$

The therapeutic use of opioid analgesics can promote undesirable effects, such as tolerance, pharmacological dependence and alterations in carbohydrate and lipid metabolization. Furthermore, according to the Centers for Disease Control and Prevention of the United States, their abuse use was associated with more than 47,000 deaths in 2017.7,8,9

For this reason, natural products represent an alternative in the use of potentially therapeutic biologically active molecules. ${ }^{7}$ The relevance of these products and their metabolites for the control of pain and other conditions is acknowledged by contemporary science, such that the primary sources of $20 \%$ to $50 \%$ of the currently used drugs are natural products, including medicinal plants. ${ }^{10}$

Monoterpenes, found in essential oils obtained from aromatic plants, are recognized by their antinociceptive effects, including in the orofacial region, when studied in animal models. ${ }^{11}$ Within this context, the therapeutic potential of geraniol has sparked much interest because its similar properties, such as liposolubility and small molecular size, can contribute to the interaction with neuronal receptors. This molecule is acyclic monoterpene alcohol obtained from medicinal plants, such as Cymbopogon nardus, Cymbopogon citratus, and Cymbopogon winterianus, whose essential oils are recognized by antinociceptive action, with a wide variety of pharmacological actions and prominent commercial use. ${ }^{12,13,14,15}$ The antinociceptive activity of geraniol was previously reported in a study conducted by La Rocca et al., ${ }^{16}$ who administered doses of 12.5, 25 , and $50 \mathrm{mg} / \mathrm{kg}$, using different methodological protocols, to assess its antinociceptive activity in an animal model. However, there are no reports in the literature on the action of geraniol on nociceptive processes involving the orofacial region. This fact led us to hypothesize that geraniol is capable of modulating orofacial pain by interacting with nociceptors involved in neuronal transmission in this region.

Therefore, the objective of the present study was to investigate the orofacial antinociceptive activity of geraniol at the aforementioned doses in an experimental nociception model in mice using glutamate, capsaicin, and formalin tests and to determine the molecular docking mechanisms based on an in silico model.

\section{Methodology}

\section{Drugs and reagents}

For conduction of in vivo testes, geraniol (Sigma-Aldrich $^{\circledast}$, St. Louis, MO, USA), morphine hydrochloride (Sigma-Aldrich ${ }^{\circledast}$, St. Louis, MO, USA), glutamate (Sigma-Aldrich ${ }^{\circledR}$, St. Louis, MO, USA), capsaicin (Sigma-Aldrich ${ }^{\circledast}$, St. Louis, MO, USA), formaldehyde (Vetec ${ }^{\circledR}$, Rio de Janeiro, RJ, Brazil), and Tween-80 (Vetec ${ }^{\circledR}$, Rio de Janeiro, RJ, Brazil) were used.

\section{Animal experimentation}

The present study was a randomized, controlled and double-blind nonclinical trial. It was approved by the animal ethics committee of the Federal University of Paraiba (CEUA-UFPB, ruling no. 068/2017).

The animals used in the experiments were healthy male adult Swiss mice (Mus musculus) weighing 25 to 35 grams and were provided by Professor Thomas George Bioterium (UFPB). The animals were subjected to a 12-hour light-dark cycle (light: 6:00 am to 6:00 pm) and provided a balanced diet and water ad libitum. Two hours before each experiment, the animals were transferred to the 
experimentation room and received only water ad libitum. The animals were not anesthetized before the induction of nociception to limit potential bias. All experiments were conducted by the same calibrated examiners in the afternoon.

The results reported by La Rocca et $a 1 .{ }^{16}$ were used to calculate the sample size. For a two-tailed study with a $5 \%$ significance level, an r-value of -0.878 (effect size), and a statistical power of $80 \%$, the required sample size calculated was 7 mice per group for a total of 105 animals.

\section{Induction of orofacial nociception}

The following experiments were performed to investigate orofacial pain in the animal model: glutamate-induced orofacial nociception, capsaicininduced orofacial nociception, and formalin-induced orofacial nociception.

At the beginning of the experiment, geraniol was administered to the test groups. The doses suggested investigating its pharmacological efficacy were based on a previous study that assessed the antinociceptive effect of geraniol in classical models (i.e., 12.5, 25, and $50 \mathrm{mg} / \mathrm{kg}$; intraperitoneal-IP). ${ }^{16}$ A solution of $\mathrm{NaCl}$ and $0.2 \%$ Tween 80 was used as a negative control, and morphine $(6 \mathrm{mg} / \mathrm{kg} \mathrm{IP})$ was used as a positive control.

Approximately 30 minutes after the administration of these substances, orofacial nociception was induced through the administration of the inducer substances to the right orofacial (perinasal) region. For the present study, the behavior analysis model was selected, which consists of observing the animals' behavior (namely, measuring the time (in seconds) that they rubbed the injected area with their front or rear limbs).

The assessment was performed using triangular wooden boxes, with two walls made of mirror and clear glass measuring $25 \mathrm{~cm}$ in height and width. A previously calibrated examiner directly observed the behaviors of the mice intensely.

The glutamate-induced nociception test was performed first. This experiment followed the protocol described by Beirith et al., ${ }^{17}$ with slight modifications. A total of $45 \mu \mathrm{l}(25 \mu \mathrm{M})$ of glutamate was injected into the upper lip (perinasal region) with a 27-gauge needle. The animals were then observed over the subsequent 15 minutes. Capsaicininduced nociception involved the subcutaneous injection of $20 \mu \mathrm{l}(2.5 \mu \mathrm{g})$ of capsaicin dissolved in ethanol, dimethyl sulfoxide and distilled water (1:1:8) into the upper lip (perinasal region) with a 27-gauge needle. Nociceptive behavior was observed for 20 minutes. ${ }^{18}$ Last, in the formalin-induced nociception test, $20 \mu \mathrm{l}$ of $20 \%$ formalin solution was injected into the right upper lip (perinasal region) with a 27-gauge needle. Nociceptive behavior was observed after injection at two time points: phase 1 or neurogenic (0-5 minutes) and phase 2 or inflammatory (15-40 minutes). ${ }^{19}$

\section{Data management and blinding}

Data management and blinding were performed to reduce possible sources of bias in data collection and analysis. The test sequence and allocation of animals into groups were randomized using the program Random Allocation 2.0.

Blinding was performed as follows: investigator A prepared the materials needed for testing and coded the animals; investigator $\mathrm{B}$ administered the substances; investigator $\mathrm{C}$, who was blinded to the substances and doses administered to the animals, performed direct intensive observation of nociceptive behavior during the period set for each inducer substance; and investigator $\mathrm{D}$, who was also blinded, then performed the statistical analysis. Finally, investigator A recoded the data analyzed by investigator $\mathrm{D}$.

\section{Euthanasia method}

Prior to euthanasia, in a private room and with the aid of sterile syringes, the animals were treated with an injection of anesthetics (thiopental, $100 \mathrm{mg}$ / $\mathrm{kg}$ IP, and lidocaine, $10 \mathrm{mg} / \mathrm{kg}$ IP). After the loss of the corneal reflex, euthanasia was performed by cervical dislocation. The euthanasia procedures were recommended by the Brazilian Euthanasia Practice Guidelines and Animal Research: Reporting of In Vivo Experiments (ARRIVE). ${ }^{20,21}$ 


\section{Molecular docking analysis: in silico}

The structure of geraniol was obtained from PubChem (https://pubchem.ncbi.nlm.nih.gov/ compound/637566\#section=Top) as a .sdf file. All receptors are coupled with an inhibitory ligand previously described in enzyme activity studies in vitro. The receptors that, once activated, trigger a biochemical cascade that culminates in nociception were selected for the present study. ${ }^{22,23,24}$

First, the following receptors and corresponding ligands were downloaded: metabotropic glutamate receptor 6 (mGluR6; PDB ID: 1S50; ligand: glutamic acid), N-methyl-D-aspartate (NMDA; PDB ID: 2A5S; ligand: glutamic acid), $\alpha$-amino-3-hydroxy-5-methyl4-isoxazolepropionic acid (AMPA; PDB ID: 3DLN; ligand: glutamic acid), mu opioid receptor $(\mu$; $\mathrm{PB}$ ID: 4DKL; ligand: morphine), kappa opioid receptor (к; PDB ID: 4DJH; ligand: JDTic), delta opioid receptor ( $\delta$; PDB ID: 4EJA; ligand: naltrindole), and transient receptor potential vanilloid receptor 1 (TRPV1; PDB ID: 5IRZ; ligand: $\mathrm{C}_{24} \mathrm{H}_{45} \mathrm{O}_{13} \mathrm{P}$ ).

Geraniol and seven ligands present in PDB proteins were drawn in the program HyperChem for Windows v. 8.0.5.5 The molecular geometries of the compounds were optimized using the molecular mechanics force field MM+ and the AM1 (Austin Model 1) semiempirical method. ${ }^{26}$

Next, geraniol was subjected to molecular docking using the software Molegro Virtual Docker v. 6.0.1-MVD. ${ }^{27}$ All the water molecules were deleted from the enzyme structure. The structures of the enzymes and compounds were prepared with the same software in the following standard parameter configuration: ligand evaluation: determination of the internal ES, internal HBond; number of runs: 10; algorithm: MolDock SE; maximum iterations: 1,500; maximum population size: 50; maximum steps: 300; distance factor: 1.0; and maximum number of poses: 5 . Coupling was performed with a $15 \AA$ radial grid and a resolution of 0.30 to cover the site of ligand binding to the protein structure. The strength of the protein-ligand interaction is expressed as the MolDock Score (MDS), in which negative scores represent stronger interactions.

The results of each calculation were analyzed to obtain the affinity energy $(\mathrm{kcal} / \mathrm{mol})$ of each ligand conformation in its respective complex; possible structural imprecisions were dismissed in the calculation.

\section{Statistical analysis}

Statistical analysis was performed with the software Statistical Package for the Social Sciences (SPSS) version 21 in a two-tailed study with a 5\% significance level. One-way analysis of variance (ANOVA) was first performed to detect the occurrence of significant differences among groups. Next, the t-test for heterogeneous variances was performed to establish which groups differed from the control.

Ethical approval was obtained from the local ethics committee of the Federal University of Paraíba, Paraíba, Brazil (Nr. 068/2017).

\section{Results}

Pretreatment with geraniol was associated with a reduction (dose-response dependent) in face-rubbing behavior induced by glutamate, formalin, and capsaicin when compared to the control group (saline).

The orofacial antinociceptive effect of geraniol was evident in the glutamate test. Doses of $25 \mathrm{mg} / \mathrm{kg}$ $(p=0.01$; mean $=23.85$; standard deviation $[S D]=15.26$; strength $=86.42 \%$; confidence interval $[\mathrm{CI}]: 0.42-3.15)$ and

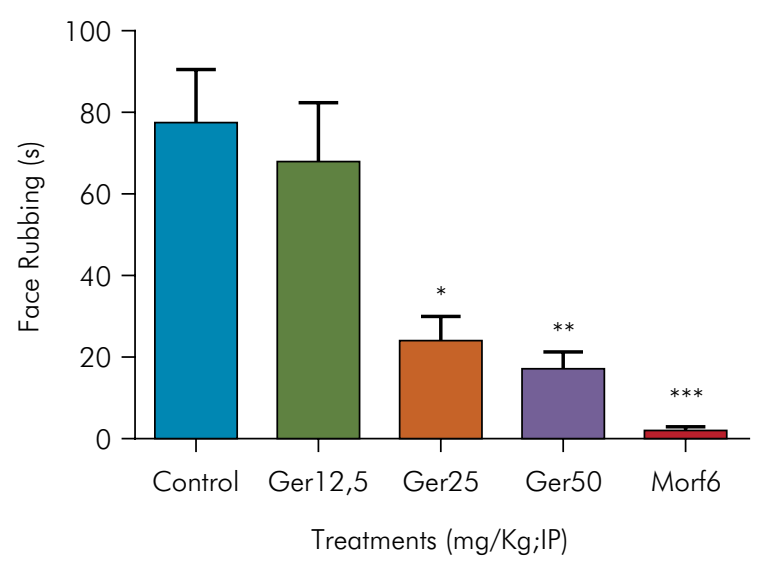

Figure 1. Effect of geraniol on glutamate-induced nociception. Control $(0.2 \%$ Tween 80$)$; geraniol $(12.5,25$ and $50 \mathrm{mg} / \mathrm{kg}$ IP); morphine (6 mg/kg IP). Values are expressed as the mean $\pm \mathrm{SD}\left(\mathrm{n}=7\right.$ in each group), $\mathrm{p}^{*}=\mathrm{n} 0.01 ; \mathrm{p}^{* *}=0.005$; $\mathrm{p}^{* * *}=0.001$ versus control (one-way ANOVA followed by the t-test for heterogeneous variances). 
$50 \mathrm{mg} / \mathrm{kg}$ ( $\mathrm{p}=0.004 ;$ mean $=17.14 ; \mathrm{SD}=10.12 ;$ strength $=94.90 \%$; CI: $0.70-3.61)$ were effective. Morphine exerted a similar effect $(\mathrm{p}=0.001$; mean $=1.5 ; \mathrm{SD}=2.6$; strength =99\%; CI: 1.26-4.58), as shown in Figure 1.

In this study, geraniol promoted a significant reduction in capsaicin-induced nociception at doses of $25 \mathrm{mg} / \mathrm{kg}$ ( $\mathrm{p}=0.003$; mean $=25.71 ; \mathrm{SD}=32.25$; strength $=95.44 \%$; CI: $0.62-3.68)$ and $50 \mathrm{mg} / \mathrm{kg}(\mathrm{p}=0.01$; mean $=5.28 ; \mathrm{SD}=12.68$; strength=98.88\%; CI: 1.16-4.40). Morphine exerted an antinociceptive effect at a dose of $6 \mathrm{mg} / \mathrm{kg}(\mathrm{p}=0.001$; mean = 1.5; $\mathrm{SD}=2.63$; strength $=99.14 \%$; CI: $1.24-4.55)$. These results are depicted in Figure 2.

In the formalin-induced nociception test, the effects of the tested substances were assessed at two different phases: neurogenic (phase 1) and inflammatory (phase 2). In the neurogenic phase, immediately after the administration of formalin, only morphine exerted a significant effect $(\mathrm{p}=0.0001$; mean $=0.833 ; \mathrm{SD}=1.16$; strength $=99.99 \%$; CI: 3.36-9.60), as shown in Figure 3.

In the inflammatory phase, geraniol, at a dose of $50 \mathrm{mg} / \mathrm{kg}$ ( $\mathrm{p}=0.01 ;$ mean $=95.66 ; \mathrm{SD}=27.69$; strength $=89.99 \% ; \mathrm{CI}: 0.53-3.62)$, and morphine, at a dose of $6 \mathrm{mg} / \mathrm{kg} \mathrm{IP}(\mathrm{p}=0.0008$; mean $=0.83 ; \mathrm{SD}=1.16$; strength $=99.79 \%$; CI: $1.90-6.30)$, reduced face-rubbing behavior, as shown in Figure 4.

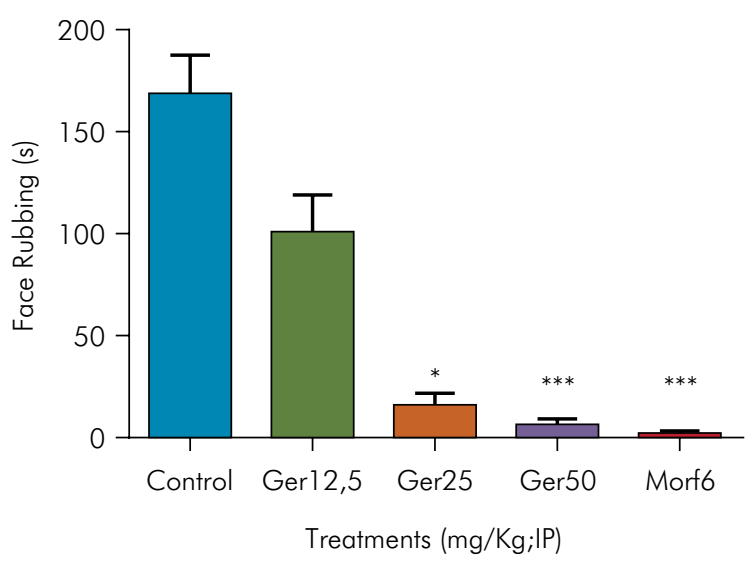

Figure 2. Effect of geraniol on capsaicin-induced nociception. Control (0.2\% Tween 80); geraniol (12.5, 25 and $50 \mathrm{mg} / \mathrm{kg}$ IP); morphine $(6 \mathrm{mg} / \mathrm{kg}$ IP). Values are expressed as the mean $\pm S D\left(n=7\right.$ in each group), $p^{*}=0.003 ; P^{* *}=0.01$; $p^{* * *}=0.001$ versus control (one-way ANOVA followed by the t-test for heterogeneous variances).
The possible interaction of geraniol with nociceptors was evaluated using the molecular anchorage method, and Table and Figure 5 describe the binding energies of geraniol with the following receptors: mGluR6 (PDB ID: 1S50), NMDA (PDB ID: 2A5S), AMPA (PDB ID: 3DLN), $\mu$ (PDB ID: 4DKL), K (PDB ID: 4DJH), $\delta$ (PDB ID: 4EJA), and TRPV1 (PDB ID: 5IRZ).

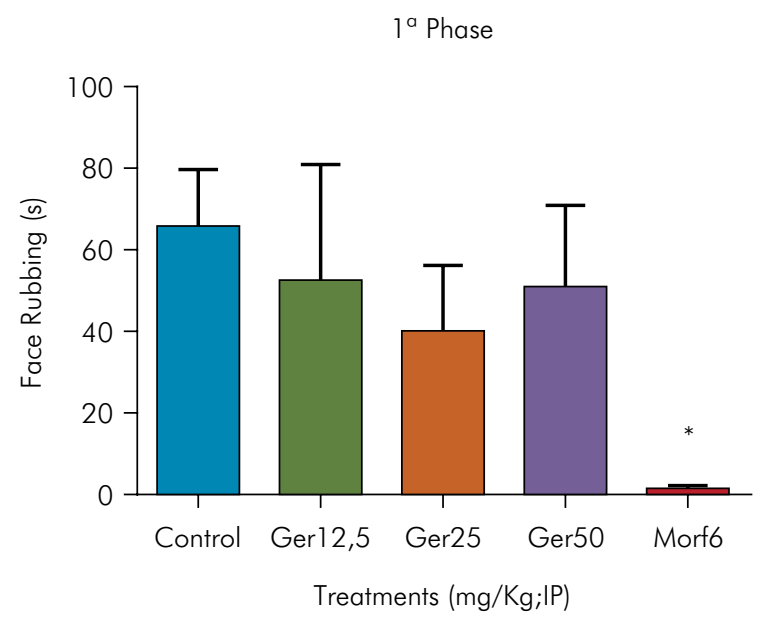

Figure 3. Effect of geraniol on formalin-induced nociception. Control (0.2\% Tween 80); geraniol (12.5, 25 and $50 \mathrm{mg} / \mathrm{kg} \mathrm{IP);}$ morphine $(6 \mathrm{mg} / \mathrm{kg} \mathrm{IP})$. Values are expressed as the mean \pm $\mathrm{SD}\left(\mathrm{n}=7\right.$ in each group); $\mathrm{p}^{*}=0.001$ versus control (one-way ANOVA, followed by the t-test for heterogeneous variances).

\section{$2^{a}$ Phase}

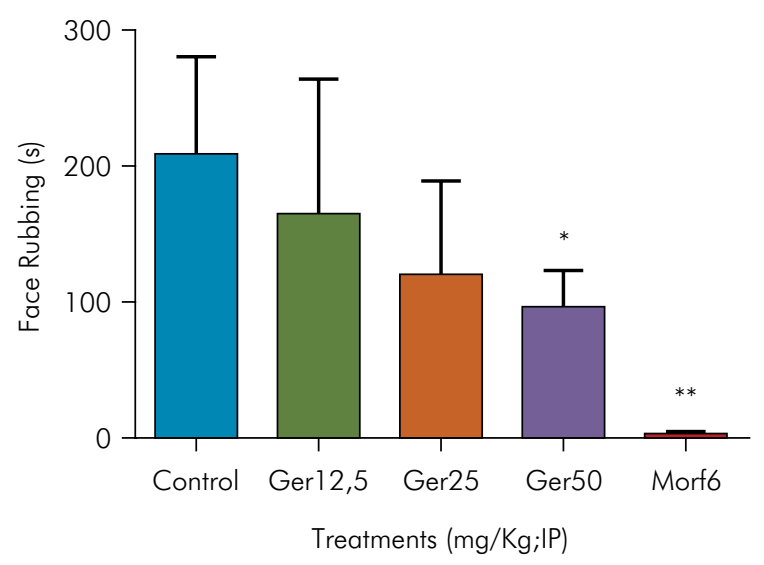

Figure 4. Effect of geraniol on formalin-induced nociception. Control (0.2\% Tween 80); geraniol (12.5, 25 and $50 \mathrm{mg} / \mathrm{kg}$ IP); morphine $(6 \mathrm{mg} / \mathrm{kg}$ IP). Values are expressed as the mean $\pm \mathrm{SD}\left(\mathrm{n}=7\right.$ in each group); $\mathrm{p}^{*}=0.01 ; \mathrm{p}^{* *}=0.0008$ versus control (one-way ANOVA followed by the t-test for heterogeneous variances). 
Table. Binding energies of geraniol to receptors.

\begin{tabular}{|c|c|c|c|c|c|c|c|}
\hline Receptores & mGlurb & NMDA & AMPA & $\mu \ddot{~}$ & Kappa & Delta & TRPV1 \\
\hline Energia $(\mathrm{Kcal} / \mathrm{mol})$ & -87.8501 & -86.4451 & -85.6755 & -57.6318 & -79.5355 & -62.349 & -68.5058 \\
\hline
\end{tabular}

Molecular docking analysis yielded high negative energy values, especially for glutamate receptors (mGluR, MDS=-87.8501), involving amino acids Leu189, Glu191, Thr143, and Arg56; NMDA (MDS=-86.4451), interacting with Val116, Gly172, Thr174, His88, and Thr116; and AMPA (MDS=-85.6755), establishing interactions with Val169, Gly172, Thr174, His88, Thr116, and Ser173. Analysis of geraniol interactions at the active sites of these receptors revealed a higher prevalence of ester and hydrogen bonds.

\section{Discussion}

Delta and $\mathrm{C}$ fibers in the orofacial region convey nociceptive stimuli to the trigeminal nerve. Animal models involving the administration of inducer substances (glutamate, capsaicin, and formalin) to this region are a relevant tool to study nociception and the development of new drugs.

This is the first study to evaluate the orofacial antinociceptive effect of geraniol. Although a previous investigation has demonstrated the antinociceptive action of this molecule ${ }^{16}$ (La Rocca et al), nerve transmission in the orofacial region has specificities. Unlike the spinal system, nociception conducted by trigeminal nerves includes a group of organs not located elsewhere in the body. Nervous processing of the orofacial region occurs at the level of the brain stem in the spinal trigeminal nuclear complex, particularly in the subnucleus caudalis. ${ }^{29}$

Geraniol presents low acute toxicity (LD50 of $3.6 \mathrm{~g} / \mathrm{kg}$ ) when administered orally to mice. ${ }^{30}$ A previous animal (mouse) study on the evaluation of acute toxicity reported that doses of $100 \mathrm{mg} / \mathrm{kg} /$ day, administered orally for 27 weeks, did not cause hematological or tissue changes. ${ }^{31}$ This evidence stimulates further pharmacological investigations of genariol, including its analgesic effect.

In the present study, geraniol at doses of 25 and $50 \mathrm{mg} / \mathrm{kg}$ promoted a significant reduction in the nociceptive activity induced by glutamate injected into the right upper lips of mice. Glutamate is the most abundant amino acid in the central nervous system (CNS). It acts as an excitatory neurotransmitter and is involved in the transmission of nociceptive stimuli through the activation of glutamatergic receptors. ${ }^{32}$

Glutamate may bind to metabotropic or ionotropic receptors. The action of the metabotropic receptors (mGluRs) is mediated by protein $\mathrm{G}$, as is the case for mGluR6. Once activated, these receptors modulate the second messenger within the intracellular biochemical cascade. In turn, ionotropic receptors, such as NMDA and AMPA, constitute the site of neurotransmitter binding as a part of an ion channel. These receptors are responsible for rapid synaptic transmission. Once activated, they cause calcium ion influx, the intracellular activation of metabolic pathways, and the production and release of nitric oxide. ${ }^{23}$ The results of the present study suggest that geraniol blocks the transmission of nociceptive stimuli along the glutamatergic pathway through the aforementioned receptors.

Capsaicin is the main component of red pepper and accounts for the burning feeling it elicits. It behaves as a proinflammatory agent by stimulating the release of neuropeptides, such as neurokinin A, substance P, and calcitonin gene-related peptide (CGRP), in the trigeminal nerve. It is an agonist of TRPV1 receptors, which are present in the A-delta and C fibers of primary afferent neurons. Once activated, these receptors promote ion calcium influx into the cells, causing membrane depolarization and consequent cell excitation. ${ }^{33,34}$ In the case of capsaicin-induced nociception, geraniol, at doses of 25 and $50 \mathrm{mg} / \mathrm{kg}$, exhibited antinociceptive activity, suggesting that its pharmacological effect may be associated with TRPV1 receptor blockade.

The formalin test is considered a valid and reliable nonclinical test to investigate the modulation of orofacial nociceptive stimuli. When administered to the right upper lips of animals, it causes episodes of face rubbing. This test is divided into two phases: phase 1 or neurogenic (0-5 minutes) and phase 2 or inflammatory (15-40 minutes). The biphasic nature 


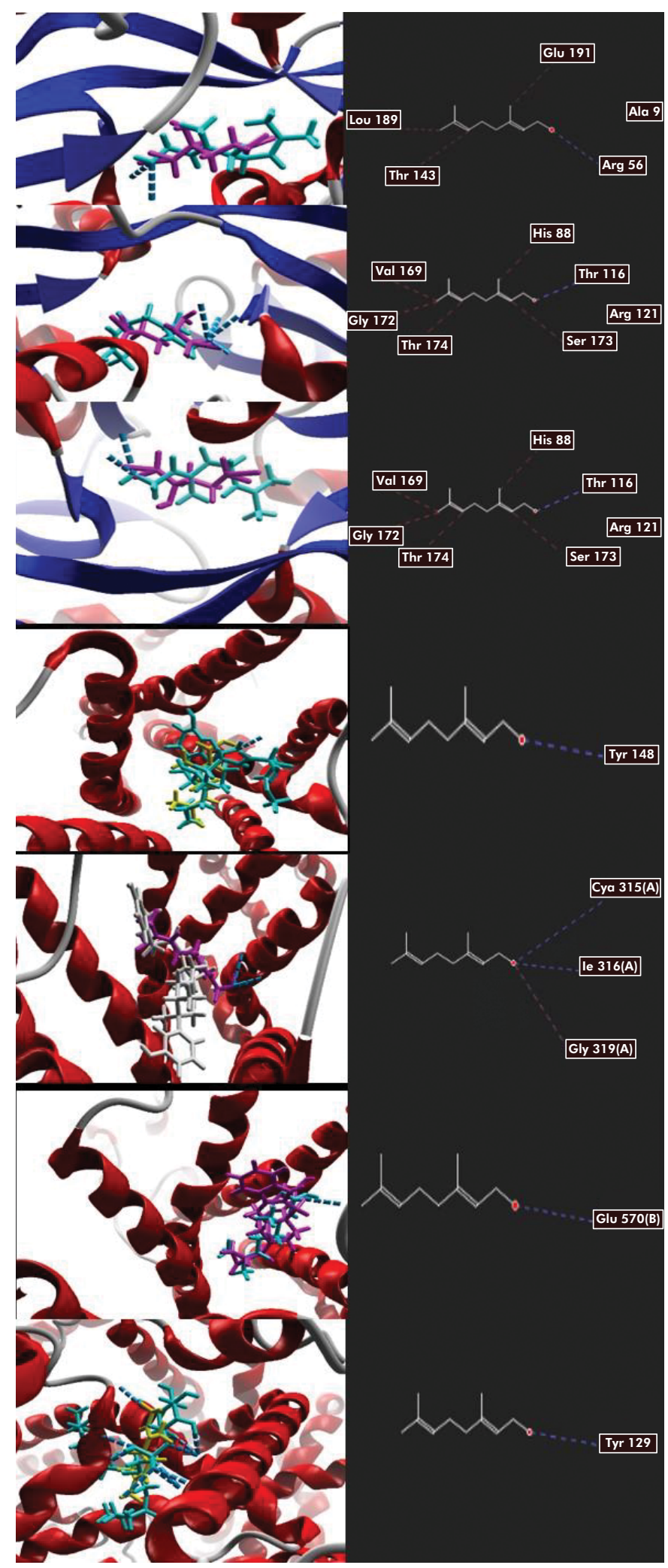

Figure 5. A - Binding of geraniol (blue) to the active site of the mGlurb receptor and its interactions. B - Interaction of geraniol (blue) on the active site of NMDA. C - Interaction of geraniol (blue) on the active site of AMPA. D - Interaction of geraniol (blue) on the active site of AMPA. E - Interaction of geraniol (pink) on the active site of opioid k. F - Interaction of geraniol (blue) on the active site of opioid $\delta$. $G$ - Interaction of geraniol (yellow) on the active site of TRPV 1 . 
of this test reflects two different mechanisms. Phase 1 corresponds to the chemical stimulation of type $\mathrm{C}$ nociceptive nerve endings, which reflects centrally mediated pain involving the release of neuropeptides such as substance $P$. The neurogenic phase is inhibited by drugs acting on the CNS, such as opioids. In this study, morphine was able to promote this effect. Phase 2 is characterized by the interaction of the central and peripheral nervous systems and involves the release of excitatory amino acids, nitric oxide, and peptides. ${ }^{35}$

The administration of geraniol promoted a reduction in orofacial nociceptive activity among the tested animals. This phenomenon occurred in phase 2 and only at a dose of $50 \mathrm{mg} / \mathrm{kg}$. In the study by La Rocca et al. ${ }^{16}$, geraniol exhibited the same behavior at the same dose. Therefore, geraniol may be an anti-inflammatory agent useful for the treatment of orofacial complex pain, with a central action. The anti-inflammatory effect of geraniol may be due to its participation in the regulation of NMDA receptors and the reduction in tumor necrosis factor alpha (TNF- $\alpha$ ) levels. ${ }^{36}$

The essential oil obtained from Cymbopogon citratus, which contains geraniol, was also able reduce formalininduced nociception in the second phase in mice when administered orally or intraperitoneally. The use of naloxone, an opposing receptor antagonist, was able to reverse the effect, suggesting possible action of this essential oil at the central and peripheral levels. ${ }^{37}$

Similarly, the essential oil of Cymbopogon winterianus, which contains $40.06 \%$ geraniol, promoted formalininduced antinociception, as evidenced by the time of leg licking, in the first and second phases of the test when administered orally at doses of 50,100 and $200 \mathrm{mg} / \mathrm{kg}$. These results corroborate the findings of this study. ${ }^{15}$

The antinociceptive activity of other monoterpenes has been reported in the literature. Silva et al. ${ }^{38}$ found that carvacrol-a monoterpene found in essential oils-and its combination with $\beta$-cyclodextrin reduced orofacial nociception in a rodent model. Using the same methods, Venâncio et al ${ }^{39}$ obtained similar results with linalool.

Brito et $a{ }^{40}$ analyzed the antinociceptive ability of citronellol, i.e., a monoterpene found in medicinal plants. The doses tested were 25,50 , and $100 \mathrm{mg} / \mathrm{kg}$, all of which exhibited this activity by activating certain areas of the CNS. Their results are similar to those in the present study, as geraniol at doses of 25 and $50 \mathrm{mg} / \mathrm{kg}$ exhibited the same effect.

In silico studies, such as molecular docking, are a fast, low-cost alternative for screening substances with potential biological activity. This method increases the probability of finding molecules with promising therapeutic use. Molecular docking helps identify possible molecular interactions and thus provides predictions for the mechanisms of action of new drugs. ${ }^{41}$

To better understand the pharmacological basis of the orofacial antinociceptive effect of geraniol, we performed molecular docking analysis that consisted of the in silico investigation of possible interactions with receptors involved in nociception modulation related to the in vivo tests. The results indicate that the analyzed molecule acted on the mGluR6, NMDA, AMPA, $\mu$-, $\mathrm{k}$ - and $\delta$-opioid, and TRPV1 receptors.

The high binding energies of geraniol to the analyzed receptors suggest an action involving the glutamatergic transduction pathway. Similarly, based on molecular docking, Santos et al. ${ }^{14}$ found that citronellol-also a monoterpene-can theoretically interact with the glutamatergic receptor GluR2. The binding of citronellol to the receptor involved high levels of energy and interaction with amino acids Arg-485, Glu-705, Thr-480, Ser-654, and Pro-478 in the binding site.

To better understand the effect of geraniol in the control of orofacial nociception, further studies involving methodologies that consider the use of antagonistic pharmacological agents and patch-clamp analysis are needed to elucidate the mechanisms of antinociception mediated by the neurotransmission pathway.

\section{Conclusion}

We conclude that geraniol exhibits orofacial antinociceptive activity, and theoretical evidence points to enhanced chemical interaction with receptors involved in the glutamatergic transduction pathway.

\section{Acknowledgment}

This study was financed in party by the Coordenação de Aperfeiçoamento de Pessoal de Nível Superior - Brasil (CAPES) - Finance Code 001. 


\section{References}

1. Shaefer JR, Khawaja SN, Bavia PF. Sex, gender, and orofacial pain. Dent Clin North Am. 2018 Oct;62(4):665-82. https://doi.org/10.1016/i.cden.2018.06.001

2. Rahimi H, Twilt M, Herlin T, Spiegel L, Pedersen TK, Kuseler A, et al. Orofacial symptoms and oral health-related quality of life in juvenile idiopathic arthritis: a two-year prospective observation study. Pediatr Rheumatol Online J. 2018 jul;16:47. https://doi.org/10.1186/s12969-018-0259-4

3. De Rossi SS. Orofacial pain: a primer. Dent Clin North Am. 2013 Jul;57(3):383-92. https://doi.org/10.1016/i.cden.2013.04.001

4. Joury E, Bernabe E, Gallagher JE, Marcenes W. Burden of orofacial pain in a socially deprived and culturally diverse area of the United Kingdom. Pain. 2018 Jul;159(7):1235-43. https://doi.org/10.1097/i.pain.0000000000001203

5. Tomoyasu Y, Higuchi H, Mori M, Takaya K, Honda Y, Yamane A, et al. Chronic orofacial pain in dental patients: retrospective investigation over 12 years. Acta Med Okayama. 2014;68(5):269-75. https://doi.org/10.18926/AMO/52895

6. Häggman-Henrikson B, Alstergren P, Davidson T, Högestätt ED, Östlund P, Tranaeus S, et al. Pharmacological treatment of oro-facial pain - health technology assessment including a systematic review with network meta-analysis. J Oral Rehabil. 2017 Oct;44(10):800-26. https://doi.org/10.1111/joor.12539

7. Petrovska BB. Historical review of medicinal plants' usage. Pharmacogn Rev. 2012 Jan;6(11):1-5. https://doi.org/10.4103/0973-7847.95849

8. Liu F, Steinkeler A. Epidemiology, diagnosis, and treatment of temporomandibular disorders. Dent Clin North Am. 2013 Jul;57(3):465-79. https://doi.org/10.1016/i.cden.2013.04.006

9. U.S. Department of Health and Human Sciences. Centers for Disease Control and Prevention. CDC in action: 2018 response to the opioid crises. Atlanta: Centers for Disease Control and Prevention Opioid Response Coordinating Unit; s.d. [cited 2020 March 11]. Available from: http://www.cdc.gov/opioids/framework/accomplishments.html

10. Newman DJ, Cragg GM. Natural products as source of new drugs from 1981 to 2014. J Nat Prod. 2016 Mar;79(3):629-61. https://doi.org/10.1021/acs.jnatprod.5b01055

11. Siqueira-Lima PS, Silva JC, Quintans JS, Antoniolli AR, Shanmugam S, Barreto RS, et al. Natural products assessed in animal models for orofacial pain - a systematic review. Rev Bras Farmacogn. 2017 Jan/Feb;27(1):124-34. https://doi.org/10.1016/i.bip.2016.06.005

12. Lei Y, Fu P, Jun X, Cheng P. Pharmacological properties od geraniol: a review. Planta Med. 2019 Jan;85(1):48-55. https://doi.org/10.1055/a-0750-6907

13. Lins LC, Santos IM, Melo MS, Menezes PP, Araújo AA, Nunes RS, et al. The anticonvulsant effect of geraniol and inclusion complex geraniol: $\beta$ - cyclodextrin. Bol Latinoam Caribe Plantas Med Aromat. 2014 Nov;13(6):557-65.

14. Santos PL, Brito RG, Oliveira MA, Quintans JS, Guimarães AG, Santos MR, et al. Docking, characterization and investigation of $\beta$-cyclodextrin complexed with citronellal, a monoterpene present in the essential oil of Cymbopogon species, as an anti-hyperalgesic agent in chronic muscle pain model. Phytomedicine. 2016 Aug;23(9):948-57. https://doi.org/10.1016/i.phymed.2016.06.007

15. Leite BL, Bonfim RR, Antoniolli AR, Thomazzi SM, Araújo AA, Blank AF, et al. Assessment of antinociceptive, antiinflammatory and antioxidant properties of Cymbopogon winterianus leaf essential oil. Pharm Biol. 2010 Oct;48(10):1164-9. https://doi.org/10.3109/13880200903280000

16. La Rocca V, da Fonsêca DV, Silva-Alves KS, Ferreira-da-Silva FW, Sousa DP, Santos PL, et al. Geraniol induces antinociceptive effects in mice evaluated in behavioural and eletrophysiological models. Basic Clin Pharmacol Toxicol. 2017 Jan;120(1):22-9. https://doi.org/10.1111/bcpt.12630

17. Beirith A, Santos AR, Calixto JB. Mechanisms underlying the nociception and paw oedema caused by injection of glutamate into the mouse paw. Brain Res. 2002 Jan;924(2):219-28. https://doi.org/10.1016/S0006-8993(01)03240-1

18. Tamaddonfard E, Tamaddonfard S, Pourbaba S. Effects of intra-fourth ventricle injection of crocin on capsaicin-induced orofacial pain in rats. Avicenna J Phytomed. 2015 Sep-Oct;5(5):450-7.

19. Quintans-Júnior LJ, Melo MS, De Sousa DP, Araujo AA, Onofre AC, Gelain DP, et al. Antinociceptive effects of citronellal in formalin-, capsaicin-, and glutamate-induced orofacial nociception in rodents and its action on nerve excitability. J Orofac Pain. 2010;24(3):305-12.

20. Kilkenny C, Browne WJ, Cuthill IC, Emerson M, Altman DG. Improving bioscience research reporting: the ARRIVE guidelines for reporting animal research. PLoS Biol. 2010 Jun;8(6):e1000412. https://doi.org/10.1371/journal.pbio.1000412

21. Conselho Nacional de Controle de Experimentação Animal - Concea. Brasília, DF. Resolução Normativa CONCEA $n^{\circ} 37$, de 15.02.2018. Diretriz da prática de eutanásia do CONCEA; 2018 . [cited 2019 January 10]. Available from: https://www.mctic. gov.br/mctic/export/sites/institucional/institucional/concea/arquivos/legislacao/resolucoes_normativas/Resolucao-Normativa-n37-Diretriz-da-Pratica-de-Eutanasia_site-concea.pdf22. Xin J, Su Y, Yang Z, He W, Shi H, Wang X, et al. Distinct roles of ASIC3 and TRPV1 receptors in electroacupuncture-induced segmental and systemic analgesia. Front Med. 2016 Dec;10(4):465-72. https://doi.org/10.1007/s11684-016-0482-7 
- Orofacial antinociceptive activity and anchorage molecular mechanism in silico of geraniol

22. Chan K, MaassenVanDenBrink A. Glutamate receptor antagonists in the management of migraine. Drugs. 2014 Jul;74(11):1165-76. https://doi.org/10.1007/s40265-014-0262-0

23. Costantino CM, Gomes I, Stockton SD Jr, Lim MP, Devi LA. Opioid receptor heteromers in analgesia. Expert Rev Mol Med. 2012 Apr;14:e9. https://doi.org/10.1017/erm.2012.5

24. Hyperchem Program Release 8.0.5 for Windows. Gainesville: Hybercube; 2008.

25. Dewar MJ, Zoebisch EG, Healy EF, Stewart JJ. AM1: a new general-purpose quantum mechanical molecular model. J Am Chem Soc. 1986 Apr;115(19):3902-9. https://doi.org/10.1021/ja00299a024

26. Docker MV. (MVD) for Windows. Aarhus: CLC Bio Company; 2013.

27. Thomsen R, Christensen MH. MolDock: a new technique for high-accuracy molecular docking. J Med Chem. 2006 Jun;49(11):3315-21. https://doi.org/10.1021/jm051197e

28. Sessle BJ. Peripheral and central mechanisms of orofacial pain and their clinical correlates. Minerva Anestesiol. 2005 Apr;71(4):117-36.

29. Jenner PM, Hagan EG, Taylor JM, Cook EL, Fitzhugh OG. Food flavoring and compounds of related structure I. Acute oral toxicity. Food Cosmet Toxicol. 1964 May;2(1):327-43. https://doi.org/10.1016/S0015-6264(64)80192-9

30. Hagan EC, Hansen WH, Fitzhugh OG, Jenner PM, Jones WI, Taylor JM, et al. Food flavourings and compounds of related structure. II. Subacute and chronic toxicity. Food Cosmet Toxicol. 1967 Apr;5(2):141-57. https://doi.org/10.1016/S0015-6264(67)82961-4

31. Nascimento JE, Morais SM, Lisboa DS, Sousa MO, Santos SA, Magalhães FE, et al. The orofacial antinociceptive effect of Kaempferol-3O-rutinoside, isolated from the plant Ouratea fieldingiana, on adult zebrafish (Danio rerio). Biomed Pharmacother. 2018 Nov;107:10306. https://doi.org/10.1016/i.biopha.2018.08.089

32. Kooshki R, Abbasnejad M, Esmaeili Mahani S, Raoof M, Moeini Aghtaei MM, Dabiri S. Orexin-A inhibits capsaicin-induced changes in cyclooxygenase-2 and brain-derived neurotrophic factor expression in trigeminal nucleus caudalis of rats. Korean J Pain. 2018 Jul;31(3):174-82. https://doi.org/10.3344/kip.2018.31.3.174

33. Komya H, Shimizu K, Noma N, Tsuboi Y, Honda K, Kanno K, et al. Role of neuron-glial interaction mediated by IL-1 $\beta$ in Ectopic Tooth Pain. J Dent. 2018 Apr;97(4):467-75. https://doi.org/10.1177/0022034517741253

34. Silva JC, Macedo LA, Souza GR, Oliveira-Júnior RG, Lima-Saraiva SR, Lavor EM, et al. Orofacial antinociceptive effect of the ethanolic extract of Annona vepretorum Mart. (Annonaceae). Z Natforsch C J Biosci. 2016;71(7-8):209-14. https://doi.org/10.1515/znc-2015-5024

35. Lv Y, Zhang L, Li N, Mai N, Zhang Y, Pan S. Geraniol promotes functional recovery and attenuates neuropathic pain in rats with spinal cord injury. Can J Physiol Pharmacol. 2017 Dec;95(12):1389-95. https://doi.org/10.1139/cjpp-2016-0528

36. Viana GS, Vale TG, Pinho RS, Matos FJ. Antinociceptive effect of the essential oil from Cymbopogon citratus in mice. J Ethnopharmacol. 2000 Jun;70(3):323-7. https://doi.org/10.1016/S0378-8741(99)00168-3

37. Silva JC, Almeida JR, Quintans JS, Gopalsamy RG, Shanmugam S, Serafini MR, et al. Enhancement of orofacial antinociceptive effect of carvacrol, a monoterpene present in oregano and thyme oils, by $\beta$-cyclodextrin inclusion complex in mice. Biomed Pharmacother. 2016 Dec;84:454-61. https://doi.org/10.1016/i.biopha.2016.09.065

38. Venâncio AM, Marchioro M, Estavam CS, Melo MS, Santana MT, Onofre AS. Ocimum basilicum leaf essential oil and (-)-linalool reduce orofacial nociception in rodents: a behavioral and electrophysiological approach. Rev Bras Farmacogn. 2011 Nov-Dec;21(6):1043-51. https://doi.org/10.1590/S0102-695X2011005000147

39. Brito RG, Santos PL, Prado DS, Santana MT, Araújo AA, Bonjardim LR, et al. Citronellol reduces orofacial nociceptive behaviour in mice - evidence of involvement of retrosplenial cortex and periaqueductal grey areas. Basic Clin Pharmacol Toxicol. 2013 Apr;112(4):215-21. https://doi.org/10.1111/bcpt.12018

40. Alves VM, Braga RC, Muratov EN, Andrade CH. Quimioinformática: uma introdução. Quim Nova. 2018 Feb;41(2):202-12. https://doi.org/10.21577/0100-4042.21070145 